\title{
Polymorphism of Murine Endogenous Proviruses Revealed by Using Virus Class-Specific Oligonucleotide Probes
}

\author{
JONATHAN P. STOYE AND JOHN M. COFFIN* \\ Department of Molecular Biology and Microbiology, Tufts University School of Medicine, Boston, Massachusetts 02111
}

Received 22 July 1987/Accepted 30 September 1987

\begin{abstract}
Inbred mice contain three classes of endogenous nonecotropic murine leukemia virus-related sequences, namely xenotropic, polytropic, and modified polytropic proviruses. Oligonucleotide probes specific for the three different classes were prepared and used to examine the diversity of endogenous sequences present in eight different strains of mice: HRS/J, BALB/cJ, A/J, AKR/J, C57BL/6J, DBA/2J, C57L/J, and C3H/HeJ. A high degree of polymorphism was observed. Overall, the strains showed between $17 \%(\mathrm{~A} / \mathrm{J}$ and $\mathrm{HRS} / \mathrm{J})$ and $65 \%(\mathrm{C57BL} / 6 \mathrm{~J}$ and $\mathrm{C57} / \mathrm{L})$ shared proviruses, and only four proviruses were present in all eight strains. The similarity among the strains is due in part to the few proviruses present in all of the strains but also represents the independent assortment of a limited set of proviruses. These oligonucleotides provide a basis for determining the stability, distribution, and mutagenic potential of nonecotropic proviruses within the mouse genome.
\end{abstract}

Germ line DNAs from all inbred strains of mice contain around 50 copies of murine leukemia virus (MuLV)-related sequences $(6,32)$. These proviruses can be classified most conveniently on the basis of the structural and biological properties of their env genes. They include ecotropic proviruses which can replicate on mouse but not nonmouse cells, xenotropic viruses which replicate on nonmouse but not mouse cells, and polytropic sequences which confer a wider host range to the recombinant viruses which are regularly isolated from highly leukemic strains of mice (35). These host ranges reflect the use of distinct receptors with different species distributions (28).

In light of the roles of these endogenous proviruses in spontaneous leukemia and as potential mutagenic agents, there has been considerable interest in defining the numbers and chromosomal locations of these sequences. A probe specific for endogenous ecotropic sequences has been used to show that most strains of mice contain either no or one endogenous ecotropic provirus, though a few strains contain more (16). Even this relatively small number has had genetic consequences for the host. Of 17 endogenous ecotropic proviruses examined in detail, two are associated with coat color mutations $(7,8,15)$. The nonecotropic proviruses have been harder to study, mainly because they are present in higher numbers (3). The use of recombinant inbred strains, coupled with the choice of appropriate restriction enzymes, has permitted genetic mapping of some proviral loci $(2,22$, 36). Interestingly, close association has been demonstrated between the presence of endogenous nonecotropic sequences and a variety of lymphocyte markers, including Thy-l on chromosome 9, Igh-C on chromosome 9, and minor histocompatibility loci on chromosomes 2,3 , and 4 , as well as a variety of lymphocyte surface antigens on chromosomes $1,2,4$, and 19. Little is known about the nature of these proviruses.

An important development in the study of nonecotropic proviruses was the preparation of probes which distinguished xenotropic from polytropic sequences (26). With the xenotropic probe it was possible to enumerate and accurately identify the xenotropic proviruses in different strains;

\footnotetext{
* Corresponding author.
}

however, the polytropic probe still reacted with too many fragments to allow unambiguous identification of each polytropic provirus (26). These probes have been used to map the chromosomal locations of a number of $\mathrm{BALB} / \mathrm{c}$ proviruses by use of somatic cell hybrids (12).

Initial studies of mouse DNA digested with a variety of different enzymes by using nonspecific probes had suggested that two families of nonecotropic, nonxenotropic proviruses are present in the mouse germ line $(9,31)$. We have recently confirmed this suggestion in studies of polytropic proviruses cloned from HRS/J mice. The two families are termed polytropic and modified polytropic (33). They are closely related yet provide env genes to different recombinant viruses and confer slightly different host ranges. Furthermore, sequence analysis suggested that it should be possible to prepare probes specific for these two virus classes. This paper reports the use of these probes to determine the numbers and relationships of MuLV-related proviral sequences in different strains of mice.

\section{MATERIALS AND METHODS}

Oligonucleotide synthesis and labeling. Oligonucleotides were synthesized by the phosphoramidite method with an Applied Biosystems model 380B DNA synthesizer and then purified by reversed-phase high-pressure liquid chromatography. Four oligonucleotides were synthesized: JS4, bases 857 to 884 of modified polytropic provirus MX33 (33); JS5, bases 857 to 884 of polytropic provirus MX27 (33); JS6, bases 1092 to 1119 of a xenotropic virus isolated from NZB mice (25); JS10, the analogous bases from MX22, an endogenous xenotropic provirus from HRS mice (unpublished data). Oligonucleotides ( $200 \mathrm{ng}$ ) were labeled with $15 \mathrm{U}$ of T4 polynucleotide kinase and $0.5 \mathrm{mCi}$ of $\left[\gamma^{-32} \mathrm{P}\right] \mathrm{ATP}(7,000$ $\mathrm{Ci} / \mathrm{mmol}$; New England Nuclear Corp.) in $20 \mu \mathrm{l}$ of $50 \mathrm{mM}$ Tris ( $\mathrm{pH}$ 7.5)-10 $\mathrm{mM} \mathrm{MgCl}_{2}-5 \mathrm{mM}$ dithiothreitol-1 $\mathrm{mM}$ spermidine- $0.1 \mathrm{mM}$ EDTA for $45 \mathrm{~min}$ at $37^{\circ} \mathrm{C}$. The endlabeled DNA probes were filtered through $0.45-\mu \mathrm{m}$ (pore size) membrane filters (Millipore Corp.) and separated from unincorporated ATP on a C18 SEP-PAK column (Waters Associates, Inc.). The specific activities of the probes were around $10^{9} \mathrm{cpm} / \mu \mathrm{g}$.

Genomic blots. Mice were purchased from the Jackson 
Laboratory, and high-molecular-weight DNA was prepared from spleen cell suspensions by conventional procedures. High-molecular-weight DNA $(10 \mu \mathrm{g})$ was digested with 100 $\mathrm{U}$ of HindIII, $100 \mathrm{U}$ of HindIII plus $100 \mathrm{U}$ of BamHI, $100 \mathrm{U}$ of EcoRI (all from Boehringer Mannheim Biochemicals), or $50 \mathrm{U}$ of $P v u I I$ (New England BioLabs, Inc.) for $14 \mathrm{~h}$ at $37^{\circ} \mathrm{C}$ and subjected to electrophoresis in $20-\mathrm{cm} 0.8 \%$ agarose gels in Tris-borate-EDTA buffer (21) at $75 \mathrm{~V}$ for $21 \mathrm{~h}$. Gels were treated sequentially with $0.25 \mathrm{~N} \mathrm{HCl}$ for 10 min, twice with $0.5 \mathrm{~N} \mathrm{NaOH}-1 \mathrm{M} \mathrm{NaCl}$ for $20 \mathrm{~min}$, and twice with $1 \mathrm{M}$ Tris hydrochloride (pH 8.0)-1.5 M NaCl for $30 \mathrm{~min}$. The DNA was transferred to nitrocellulose paper for $16 \mathrm{~h}$ in $20 \times \mathrm{SSC}$ $(1 \times \mathrm{SSC}$ is $0.15 \mathrm{M} \mathrm{NaCl}$ plus $0.015 \mathrm{M}$ sodium citrate). Filters were baked for $2 \mathrm{~h}$ at $80^{\circ} \mathrm{C}$ in vacuo and prehybridized for $4 \mathrm{~h}$ in $6 \times \mathrm{NET}(1 \times \mathrm{NET}$ is $0.15 \mathrm{M} \mathrm{NaCl}, 0.03 \mathrm{M}$ Tris hydrochloride [pH 8.0], and $1 \mathrm{mM}$ EDTA)-10 $\times$ Denhardt solution $(1 \times$ Denhardt solution is $0.02 \%$ bovine serum albumin, $0.02 \%$ polyvinyl chloride, and $0.02 \%$ Ficoll) $-0.5 \%$ Nonidet P-40-0.2\% sodium dodecyl sulfate-100 $\mu \mathrm{g}$ of salmon sperm DNA per ml-50 $\mu \mathrm{g}$ of Saccharomyces cerevisiae RNA per $\mathrm{ml}$ at $62^{\circ} \mathrm{C}$. Denatured probe $\left(10^{6} \mathrm{cpm}\right)$ in 5 $\mathrm{ml}$ of fresh hybridization solution was added, and hybridizations were allowed to proceed for $18 \mathrm{~h}$ at $62^{\circ} \mathrm{C}$. Higher concentrations of oligonucleotide led to high backgrounds with no enhancement of specific signal. Filters were then washed four times in $2 \times \mathrm{SSC}-0.1 \%$ sodium dodecyl sulfate at room temperature, followed by two 30 -min washes in $1 \times$ SSC $-0.1 \%$ sodium dodecyl sulfate at $65^{\circ} \mathrm{C}$. Filters were dried and exposed at $-70^{\circ} \mathrm{C}$ for 5 to 15 days with a Cronex Lightning-Plus (E. I. du Pont de Nemours \& Co.) intensifying screen. Alternatively, filters were probed with a nicktranslated plasmid containing the 622-base-pair (bp) BamHIto-EcoRI env fragment of MCF 247 (13) cloned into pMC874 (4). In this case, the stringent $65^{\circ} \mathrm{C}$ washes were in $0.1 \times$ SSC $-0.1 \%$ sodium dodecyl sulfate.

DNA sequencing. DNA sequences were determined by the dideoxy chain terminator method (29) using buffer gradient gels (1) and $\left[\alpha{ }^{32} \mathrm{P}\right] \mathrm{dATP}$ (New England Nuclear Corp.). DNA samples to be sequenced were subcloned into M13 vector mp8 or mp9 (23).

\section{RESULTS}

Characterization of class-specific oligonucleotide probes. To study the distribution and inheritance of murine endogenous proviruses, it was necessary to distinguish different subsets of closely related endogenous sequence. We have recently demonstrated that $\mathrm{HRS} / \mathrm{J}$ mice contain three classes of nonecotropic MuLV-related provirus; namely, xenotropic, polytropic, and modified polytropic viruses (33). A number of linked characteristics allow assignment of cloned proviruses to one of these three classes (Fig. 1A). Polytropic and modified polytropic proviruses contain a BamHI site $80 \mathrm{bp}$ upstream of env which is absent in xenotropic proviruses. Both classes of polytropic provirus have a longer long terminal repeat (LTR) than the xenotropic viruses, caused by insertion of a 150 - to 190 -bp sequence $(17,27)$. Polytropic and modified polytropic proviruses differ by the presence or absence of a HindIII site toward the $3^{\prime}$ end of the pol gene (33).

Although these differences allowed us to classify the cloned proviruses, they could not be used to study virus inheritance at the genomic level. More useful were differences revealed by sequence analyses of env genes of polytropic and modified polytropic provirus clones (33). These studies showed that the major sequence difference between
A.

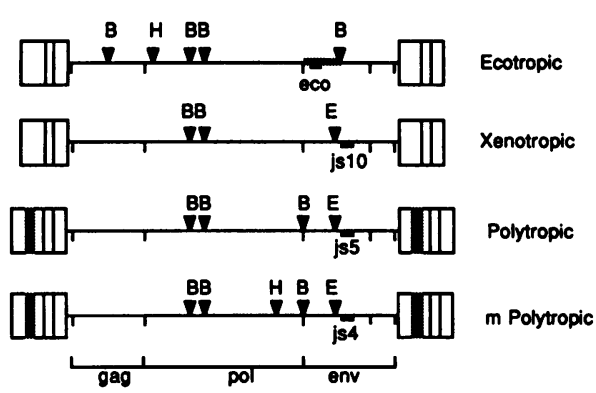

B.

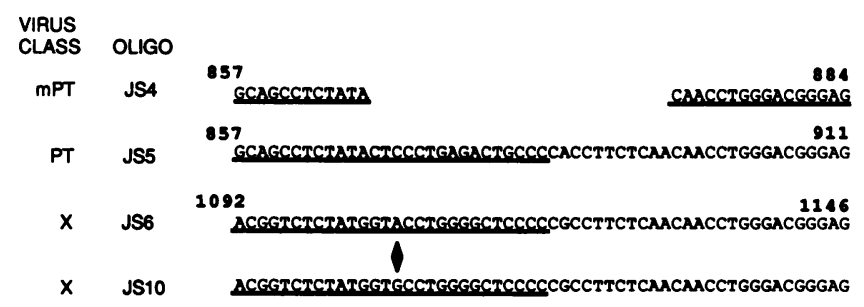

FIG. 1. Class-specific oligonucleotide probes for endogenous nonecotropic proviruses. (A) The structures of endogenous xenotropic, polytropic, and modified polytropic proviruses are shown. Features shown include the restriction sites for EcoRI (E), BamHI (B), and HindIII (H); the approximate positions of the gag, pol, and env genes and the relative sizes of the LTRs; and the positions of the oligonucleotide probes (JS4, JS5, and JS10) described in this paper. The black boxes within the LTRs of the polytropic and modified polytropic viruses corresponded to the 190-bp inserted sequence $(17,27,33)$. (B) The sequences of the regions of $\mathrm{gp} 70$ of the nonecotropic proviruses which include the class-specific oligonucleotide (OLIGO) probe are shown. The bases underlined correspond to the 28-base oligonucleotide probes specific for polytropic deleted (mPT), polytropic (PT), and xenotropic (X) viruses. The symbol $\bullet$ indicates the single-base difference between the two xenotropic proviruses. The sequences from bases 857 to 884 of MX33 (a modified polytropic provirus) (33), bases 857 to 911 of MX27 (a polytropic provirus) (33), bases 1092 to 1146 of a xenotropic virus (25), and the corresponding region of MX22 (unpublished data) are shown.

the two classes was a 27-bp deletion in the modified polytropic class. This region is shown in Fig. 1B. Comparison with the sequence of the corresponding region of a xenotropic virus isolated from NZB mice (25) also showed sequence divergence (Fig. 1B). This analysis suggested that it should be possible to prepare oligonucleotide probes specific for the three classes. We therefore synthesized three oligonucleotides, JS4 (modified polytropic), JS5 (polytropic), and JS6 (xenotropic), each 28 bases long, corresponding to the underlined sequences in Fig. 1B. These oligonucleotides were ${ }^{32} \mathrm{P}$ labeled and tested for hybridization to cloned HRS/J proviruses of each class. The three probes were hybridized to parallel Southern transfers carrying plasmid DNAs from the modified polytropic clones MX11, MX12, MX13, MX17, and MX33 (33); the polytropic clones MX21 and MX27 (33) and MCF-247 (13); and the xenotropic clones MX22, MX29, and MX30 (33); as well as the NZB-X clone (25). Hybridization and wash conditions were determined (see Materials and Methods) which allowed specific detection of the three virus classes. All of the probes provided the desired specificity, except JS6, which reacted with only two of three xenotropic proviruses (MX29 and MX30) cloned 


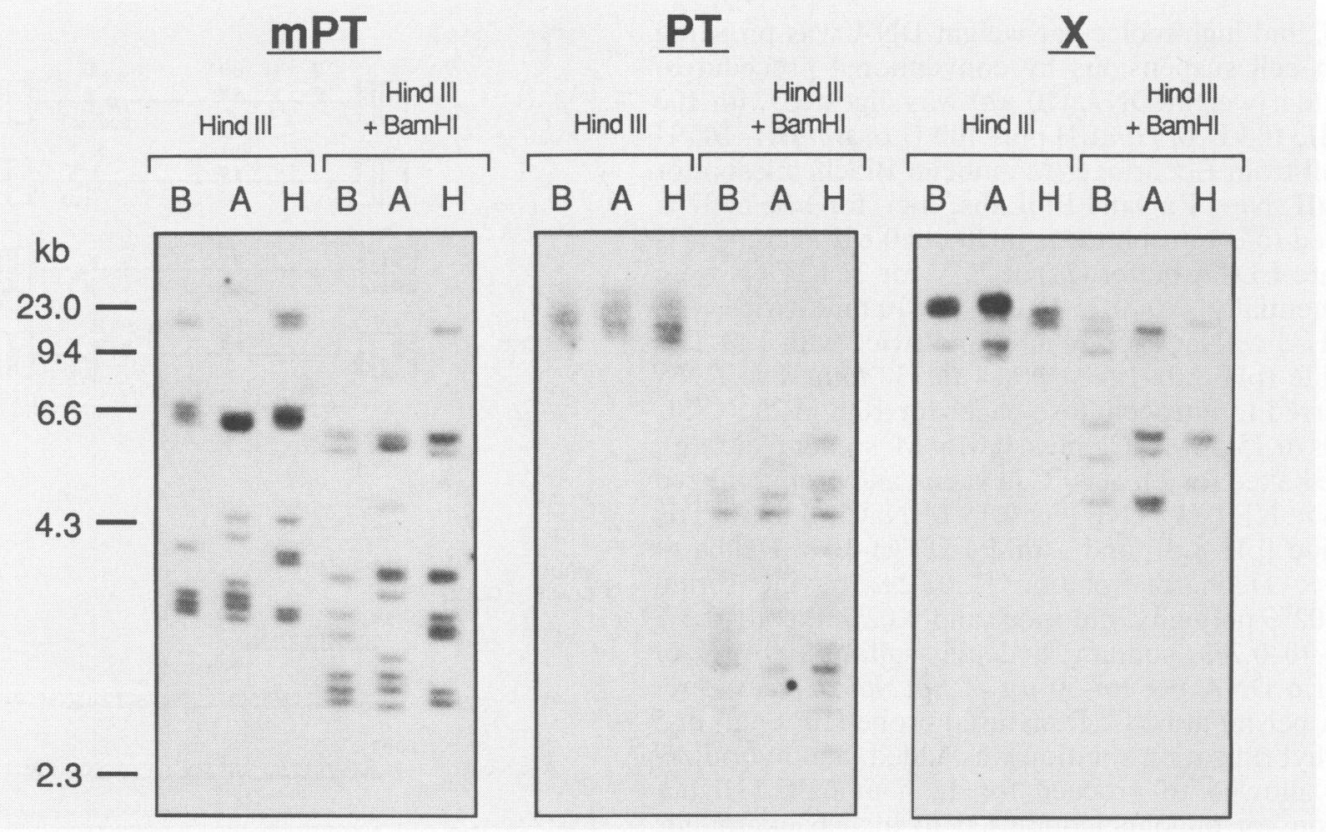

FIG. 2. Detection of endogenous proviruses with class-specific oligonucleotide probes. Identical blots of BALB/c (B), AKR/J (A), and HRS/J (H) DNAs digested with HindIII or HindIII plus BamHI were probed with labeled oligonucleotides JS4 (modified polytropic [mPT]), JS5 (polytropic [PT]), and JS10 (xenotropic [X]). The mobility of HindIII-digested lambda mitochondrial DNA markers is shown on the left $(\mathrm{kb}$, kilobases). Exposure was for 5 days with an intensifying screen.

from HRS/J mice (data not shown). Sequence analysis of the nonreactive clone (MX22) showed a 1-bp change from the NZB xenotropic virus (Fig. 1B). Therefore, we synthesized a fourth oligonucleotide, JS10, which differed by this base from JS6. Under the hybridization conditions established for JS4, JS5, and JS6, this probe recognized both homologous sequences and those reactive with JS6 in HRS/J DNA (data not shown), presumably because a guanidine-thymidine match is less destabilizing than an adenine-cytosine match. Consequently, we used JS10 or an equimolar mixture of JS6 and JS10 in studies to detect xenotropic sequences.

To test the utility of these probes for quantitating endogenous sequences and to ask whether the HRS/J-derived probes would react with endogenous proviruses present in other strains, we hybridized genomic blots of DNA from $\mathrm{HRS} / \mathrm{J}, \mathrm{BALB} / \mathrm{cJ}$, and $\mathrm{AKR} / \mathrm{J}$ mice, digested with $\mathrm{HindIII}$ or HindIII plus BamHI, with the three probes (Fig. 2). On the basis of the distribution of these restriction sites (Fig. 1B), we can make two predictions concerning the sizes of the reactive fragments. (i) Since xenotropic and polytropic proviruses do not contain an internal HindIII site, HindIII fragments that react with JS5 and JS10 should, on the whole, be larger than those that react with JS4. This prediction proved correct. No JS5- or JS10-reactive HindIII fragments smaller than 8.8 kilobases, the size of an intact provirus, were seen (Fig. 2), whereas many of the JS4-reactive HindIII fragments were smaller than 8.8 kilobases. (ii) The HindIIIplus-BamHI fragments containing polytropic and modified polytropic proviral sequences tended to be smaller than the xenotropic sequences, reflecting the absence of the BamHI site at 6.2 kilobases in the xenotropic provirus. The data (Fig. 2) show clearly that the oligonucleotide probes can be used to detect the different families of endogenous nonecotropic proviruses, not only in HRS/J but also in other inbred strains, implying that the divergence between the different virus classes predates the inbreeding of mice.

We next wanted to ask whether our oligonucleotide probes detected all or only a fraction of the nonecotropic MuLV-related proviruses present in the mouse germ line. To answer this question, we compared blots probed with a mixture of the three oligonucleotide probes and with a broadly reactive nonecotropic-virus-specific probe akin to pXenv (3). As expected, the patterns generated were complex (Fig. 3). However, this side-by-side comparison revealed that our oligonucleotide probes react with most, if not all, endogenous nonecotropic proviruses, even though the probes used hybridized to different regions of the env gene.

Strain distribution of nonecotropic proviruses. Our initial studies with $\mathrm{HRS} / \mathrm{J}, \mathrm{AKR} / \mathrm{J}$, and BALB/cJ mice (Fig. 2) showed significant heterogeneity of proviral content among different strains. We wanted to examine this question further with a larger panel of mice, with an eye to eventual genetic studies of proviral inheritance using recombinant inbred strains. For this reason, we examined EcoRI-digested DNAs from A/J, AKR/J, C57BL/6J, DBA/2J, C57L/J, and C3H/HeJ mice, all of which have been used to found recombinant inbred lines (24), as well as from BALB/cJ and HRS/J mice. Figures 4 to 6 show that within each proviral class there is a high degree of heterogeneity of proviral content as judged by the mobilities of the reactive fragments. There are clearly no xenotropic proviruses common to all eight strains (Fig. 6), and not more than one (modified polytropic, Fig. 4) or three (polytropic, Fig. 5) members of the other two classes appear to be shared by all of the strains. Similar results were obtained in studies of DNAs digested with PvuII, an enzyme which cuts all nonecotropic proviruses just $3^{\prime}$ of the conserved EcoRI site (Fig. 4B, data not shown).

We tabulated (Table 1) the numbers of each class of provirus present in the eight strains. The strains contain roughly equal numbers ( 5 to 16 ) of xenotropic and modified polytropic proviruses and somewhat more (14 to 22$)$ polytropic sequences. The total number of nonecotropic proviruses detected by these probes ranged from $25(\mathrm{C} 3 \mathrm{H} / \mathrm{HeJ})$ to 48 (C57BL/6J). 


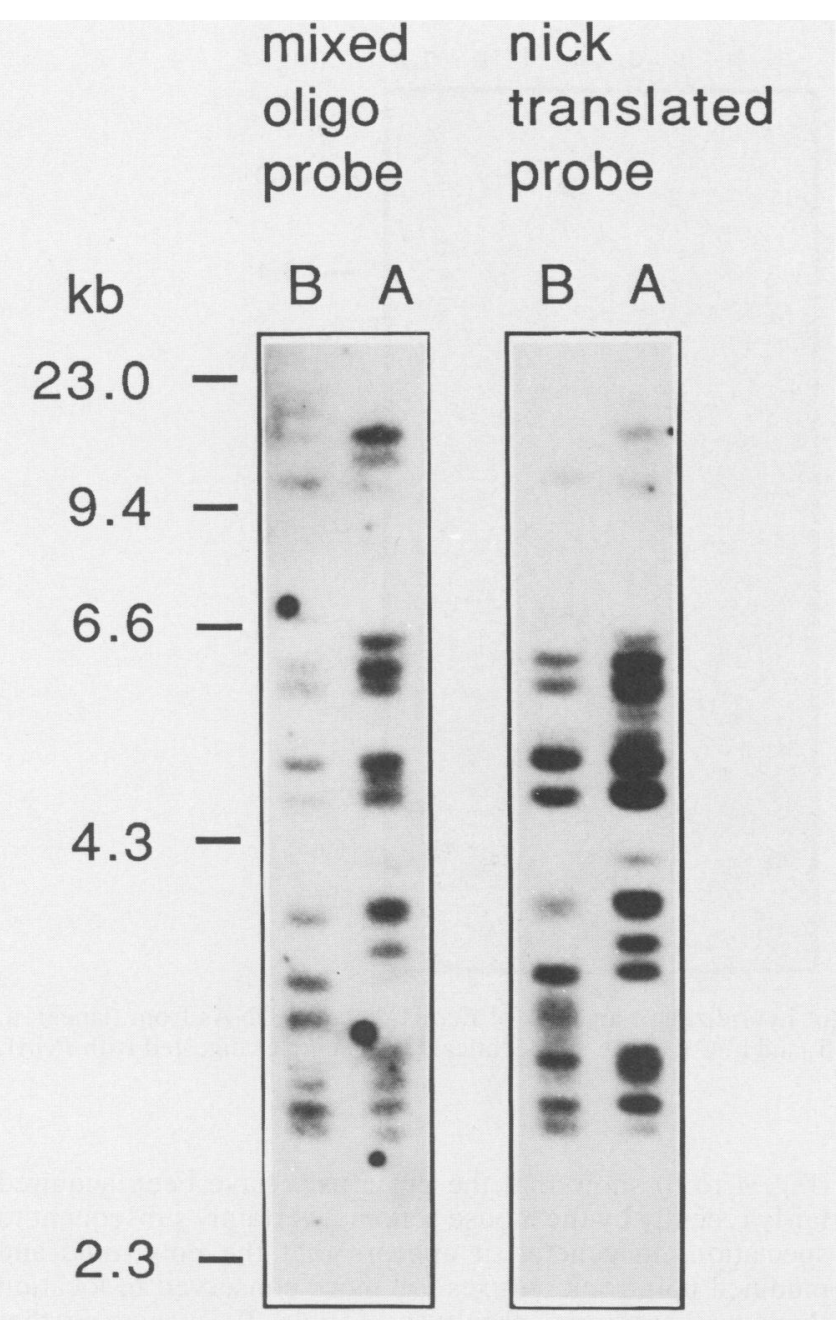

FIG. 3. Comparison of env gene probes. Parallel blots of BALB/c (B) and AKR/J (A) DNAs digested with HindIII plus BamHI were probed with a mixture of labeled JS4, JS5, and JS10 or with a nick-translated probe corresponding to the 622-bp BamHIEcoRI env fragment of MCF 247. Exposure with an intensifying screen was for 5 days with the mixed probe and 1 day with the nick-translated probe. A transfer artifact obscures the top two bands of the BALB/c sample probed with the nick-translated probe. They could be seen on a much longer exposure. kb, Kilobases.

We also attempted to compare the individual proviral contents of the different strains. This analysis was complicated by apparent differences in mobility caused by different DNA concentrations and by our inability to determine whether similar mobilities arise by chance or reflect the presence of a shared provirus. Thus, the numbers in Table 2 represent a maximum estimate of the number of shared proviruses, and it would not be surprising if rigorous genetic analyses resulted in a lowering of these numbers. Two pairs of strains, C57BL/6J and C57L/J and BALB/cJ and $\mathrm{HRS} / \mathrm{J}$, share around 60 to $70 \%$ of their proviruses, whereas most other pairwise comparisons show 20 to $50 \%$ relatedness.

\section{DISCUSSION}

Endogenous MuLV-related proviruses are associated with a number of different biological phenomena in mice. Despite this, they are poorly understood in terms of their number, type, and distribution. We describe here an approach that should prove useful for addressing these issues. A number of lines of evidence suggest that we can detect most of the nonecotropic proviruses present in the germ line of mice. (i) The combination of the three probes reacted with all or almost all of the fragments detected with the nonspecific env probe (Fig. 3). (ii) All sequenced endogenous virus genomes isolated from mice in recombinant viruses contain one or another of the sequences. The JS5 sequence is present in six of seven mink cell focus-forming viruses derived from a variety of strains (33), and the remaining mink cell focusforming virus contains the sequence corresponding to JS4 and presumably arose by recombination with an endogenous modified polytropic virus (33). (iii) We cloned 22 nonecotropic env genes from HRS/J mice, and all of the clones reacted with one or another of the probes. We sequenced the appropriate region of five independent endogenous modified polytropic clones, and they all contain the JS4 sequence (33). Also, despite a one-base mismatch with at least one xenotropic virus, JS10 reacted with all of our cloned xenotropic proviruses and gave estimates of the endogenous xenotropic virus contents of a number of strains very similar to those obtained with the xenotropic virus-specific probe derived by O'Neill and collaborators (26).

It should be noted that the probes do not detect proviruses that contain deletions in env, and a number of these are clearly present within the mouse germ line. We have cloned four proviral fragments from HRS/J mice lacking all of $e n v$ (manuscript in preparation), and others have demonstrated the expression of such proviruses in $129 / \mathrm{J}$ mice (20). We have also cloned three solo LTRs from HRS/J DNA. These presumably result from recombination between the two LTRs of endogenous proviruses, followed by fixation during subsequent inbreeding. At present it is difficult to make a precise estimate of the number of MuLV integrations which we cannot detect with our oligonucleotide probes; however, hybridization analysis with an MuLV-specific LTR probe suggests that the number of such sequences is probably less than half that of the env-containing proviruses present in the germ line (in preparation). A second potential limitation to the utility of the oligonucleotide probes stems from an inability to distinguish different subclasses of endogenous sequences with similar structures but different biological properties. We are currently addressing this issue in a detailed study of all of the endogenous proviruses we have cloned from $\mathrm{HRS} / \mathrm{J}$ mice.

Entry of endogenous proviruses into the mouse germ line. The polymorphisms observed in the endogenous nonecotropic proviruses present in different strains of inbred mice

TABLE 1. Total nonecotropic proviral contents of eight inbred strains $^{a}$

\begin{tabular}{lccc}
\hline \multirow{2}{*}{ Strain } & \multicolumn{3}{c}{ No. of reactive bands } \\
\cline { 2 - 4 } & $\begin{array}{c}\text { Modified } \\
\text { polytropic }\end{array}$ & Polytropic & Xenotropic \\
\hline HRS/J & 11 & 21 & 5 \\
BALB/cJ & 8 & 16 & 8 \\
A/J & 9 & 20 & 9 \\
AKR/J & 11 & 17 & 11 \\
C57BL/6J & 12 & 22 & 14 \\
DBA/2J & 11 & 16 & 8 \\
C57L/J & 10 & 16 & 16 \\
C3H/HeJ & 6 & 14 & 5 \\
\hline
\end{tabular}

${ }^{a}$ The data are from the blots shown in Fig. 4 to 6 , as well as from parallel PvuII digests. 


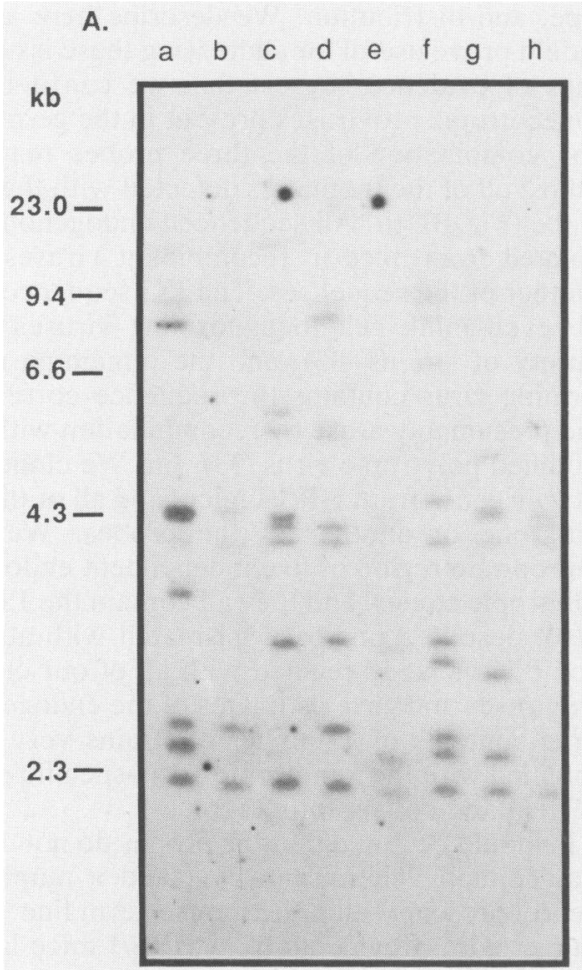

B.

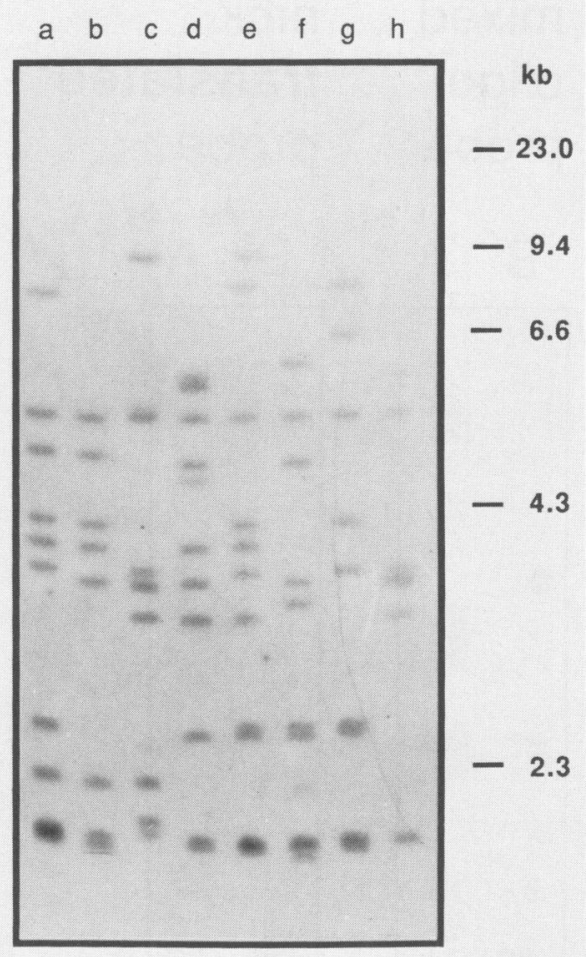

FIG. 4. Modified polytropic provirus content of eight strains. (A) Blot hybridization analysis of EcoRI-digested DNAs from (lanes): a, HRS/J; b, BALB/cJ; c, A/J; d, AKR/J; e, C57BL/6J; f, DBA/2J; g, C57L/J; and h, C3H/HeJ. (B) Identical DNA samples digested with PvuII. The blots were probed with JS4. kb, Kilobases.

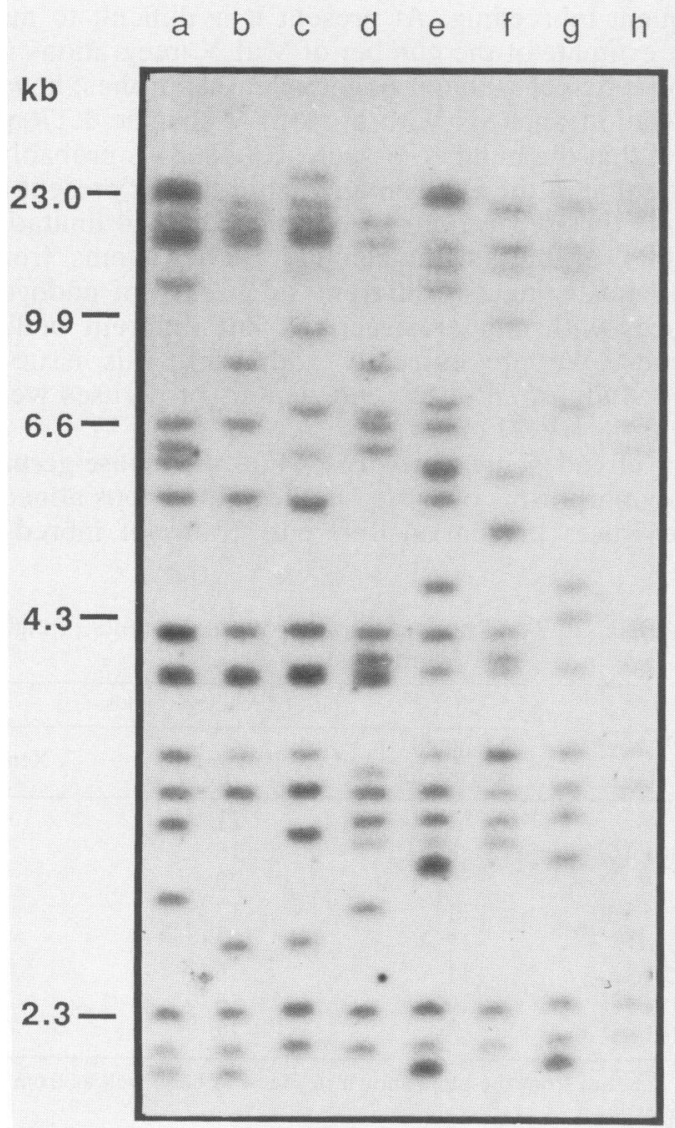

(Fig. 4 to 6) show that the proviruses have been acquired fairly recently by the mouse genome, certainly subsequent to speciation. In general, it appears that the polytropic and modified polytropic viruses are more conserved in location than the xenotropic proviruses (Table 2), suggesting that entry of the former classes into the germ line may predate that of the xenotropic sequences.

We assume, but have not formally proven, that differences in the pattern of reactive fragments with the different strains reflect differences in proviral content. It remains possible that restriction site polymorphisms caused by mutation subsequent to viral integration account for some of the differences observed. However, two lines of evidence argue against this possibility as a major source of diversity. (i) Extensive studies using flanking sequence probes to three endogenous proviruses have shown no evidence of such polymorphisms (unpublished data). (ii) We sequenced a 300 -bp sequence within the $e n v$ gene of five different endogenous modified polytropic proviruses and did not see a single base different between these clones (33), arguing against significant mutation rates following integration.

$\mathrm{C} 57 \mathrm{BL} / 6 \mathrm{~J}$ and $\mathrm{C} 57 \mathrm{~L} / \mathrm{J}$ mice show the highest conservation of proviral sequences, with about $70 \%$ of common proviruses (Table 2). This is not surprising, because both lines were derived from progeny from a single cross (24). BALB/c and $\mathrm{HRS} / \mathrm{J}$ are also related (E. L. Green, personal communication cited in reference 16 ), and this is reflected in the $60 \%$ similarity of proviral fragments in the two strains. Other

FIG. 5. Polytropic provirus content of eight strains, as in Fig. 4. The blot was probed with JS5. kb, Kilobases. 


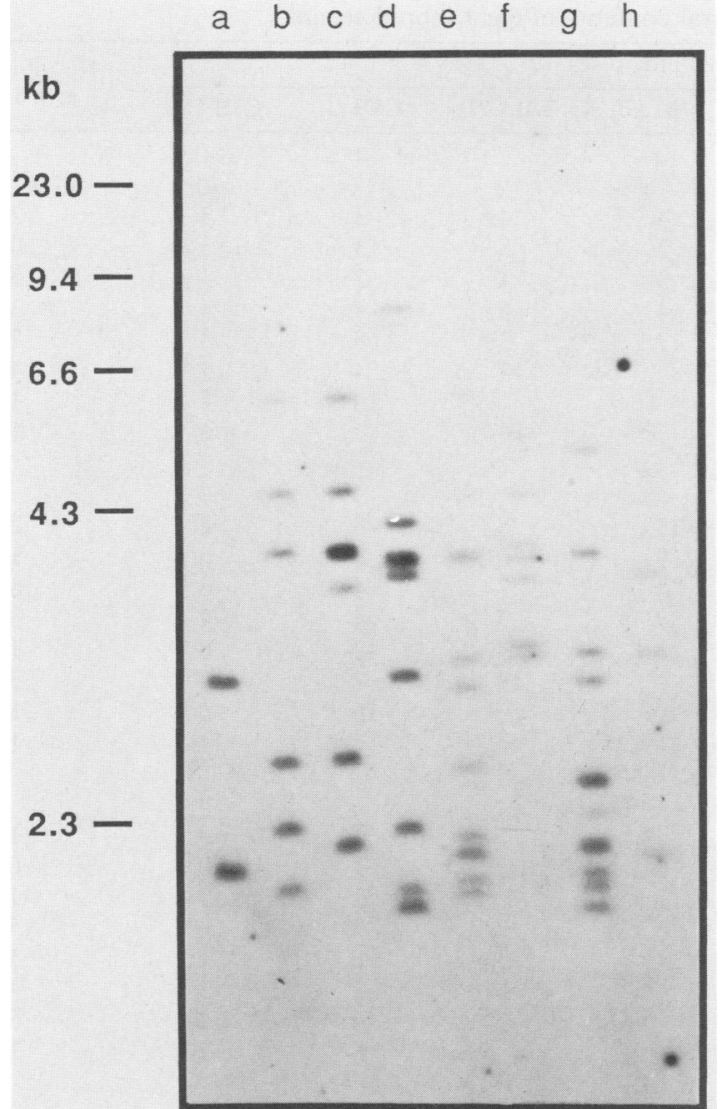

FIG. 6. Xenotropic provirus content of eight strains, as in Fig. 4. The blot was probed with JS6 and JS10. kb, Kilobases.

strains share between 20 and $50 \%$ of their proviral sequences. It does not appear that this similarity is due mainly to a few proviruses present in all of the strains, with the rest being unique. Rather, it seems to represent the independent assortment of a limited set of proviruses in a manner analogous to differential fixation of genetic markers during the derivation of recombinant inbred strains. Analysis of mouse mitochondrial DNAs has suggested that most inbred strains share a single female ancestor $(10)$, which was alive in England around 1850. Thus, it is tempting to speculate that many of the endogenous proviruses were also derived from this single female.

Differences in proviral content between two strains of mice reflect two processes; one is differential fixation of proviruses in the germ line during inbreeding, and the other is the mobility of proviruses. Within the confines of the usual genetic experiment spanning a few generations, the proviruses are reasonably stable in structure and location $(16,19$, 34); however, in evolutionary terms they represent a highly mobile group of elements. All strains of mice contain a number of apparently unique proviruses which might reflect the relatively recent acquisition of novel proviruses. Proviruses can also be lost by homologous recombination within the LTRs (7), and the resulting solo LTRs become fixed within the germ line; using a cellular flanking sequence probe specific to a provirus cloned from $\mathrm{HRS} / \mathrm{J}$ mice, we have shown that all members of the $\mathrm{C} 57$ family contain that provirus, except for C57BL/6, which contains only a solo LTR (in preparation). We plan to study the question of provirus gain and loss by using the specific oligonucleotide probes to examine the proviral contents of different substrains of the common inbred strains which were separated from one another after sufficient generations of inbreeding to eliminate differences in proviral content due to differential fixation.

How did these nonecotropic proviruses enter the germ line? Evidence from studies of ecotropic provirus amplification strongly suggests a mechanism based on infection of germ cells $(14,32)$. Polytropic and modified polytropic proviruses have the host range potential to infect mouse cells $(28,35$; data not shown); however, no infectious nonrecombinant viruses of these classes have been isolated. This may reflect inherent replication defects caused, say, by the 190bp insertion in their LTRs $(17,27)$; alternatively, it may reflect the presence of deletion or point mutations within the different endogenous sequences. Xenotropic proviruses present a different problem, since the inbred strains of mice lack a receptor for xenotropic gp70 $(18,28)$. However, wild mice do possess a receptor for xenotropic viruses (18), and it seems possible that xenotropic viruses were originally introduced via this receptor and fixed in the germ line during subsequent inbreeding, while the receptor was lost. Alternatively, they might have been made capable of infecting mouse cells by phenotypic mixing with polytropic or ecotropic viruses.

Genetic consequences of endogenous viruses. The ability to identify unambiguously all members of the group of endogenous proviruses should prove valuable to the genetic analysis of mice. By virtue of their replication cycle, retroviruses can act as insertional mutagens in both somatic and germ line cells. Not only do they activate or suppress expression of normal cellular genes, they can also provide useful tags for subsequent isolation of the affected genes. Thus, viral infection of germ cells and generation of endogenous proviruses can contribute to the genetic diversity of inbred strains of mice and might prove to be an important factor in the reportedly high rates of genetic variation in mice (11). For example, infection of early embryos with Moloney MuLV has resulted in the production of a variety of strains with different phenotypes, among them the homozygous, lethal Mov-13 strain, which contains Moloney MuLV within the $\alpha(1)$ collagen gene (30). Furthermore, at least one and possibly two coat color mutations also resulted from insertions of ecotropic proviruses $(7,8,15,30 \mathrm{a})$.

The studies with ecotropic proviruses were possible only because specific probes are available (5). Although nonecotropic viruses could represent a much richer source of such mutations, detailed studies have not been possible because of the absence of such probes. Thus, the oligonucleotides synthesized on the basis of the sequences we have determined will be used to extend this approach to nonecotropic endogenous viruses. The results (Table 2 ) show that, even though a number of endogenous loci are shared among any two of the strains examined, there are numerous differences as judged by the size differences of the reactive fragments. For example, BALB/c contains 32 and AKR contains 39 endogenous nonecotropic proviruses, of which 14 appear to be shared between the two strains. This leaves 43 virally induced polymorphisms which can serve as genetic markers. Considering the precedent with the much smaller number of ecotropic proviruses, it is not unlikely that the inheritance of endogenous proviruses in different strains of mice played a significant role in generating genetic diversity among them. A straightforward genetic analysis using recombinant inbred strains is likely both to reveal the basis of this diversity and to provide tags for isolating the relevant regions. In addition, 
TABLE 2. Comparison of the nonecotropic proviral contents of eight inbred strains ${ }^{a}$

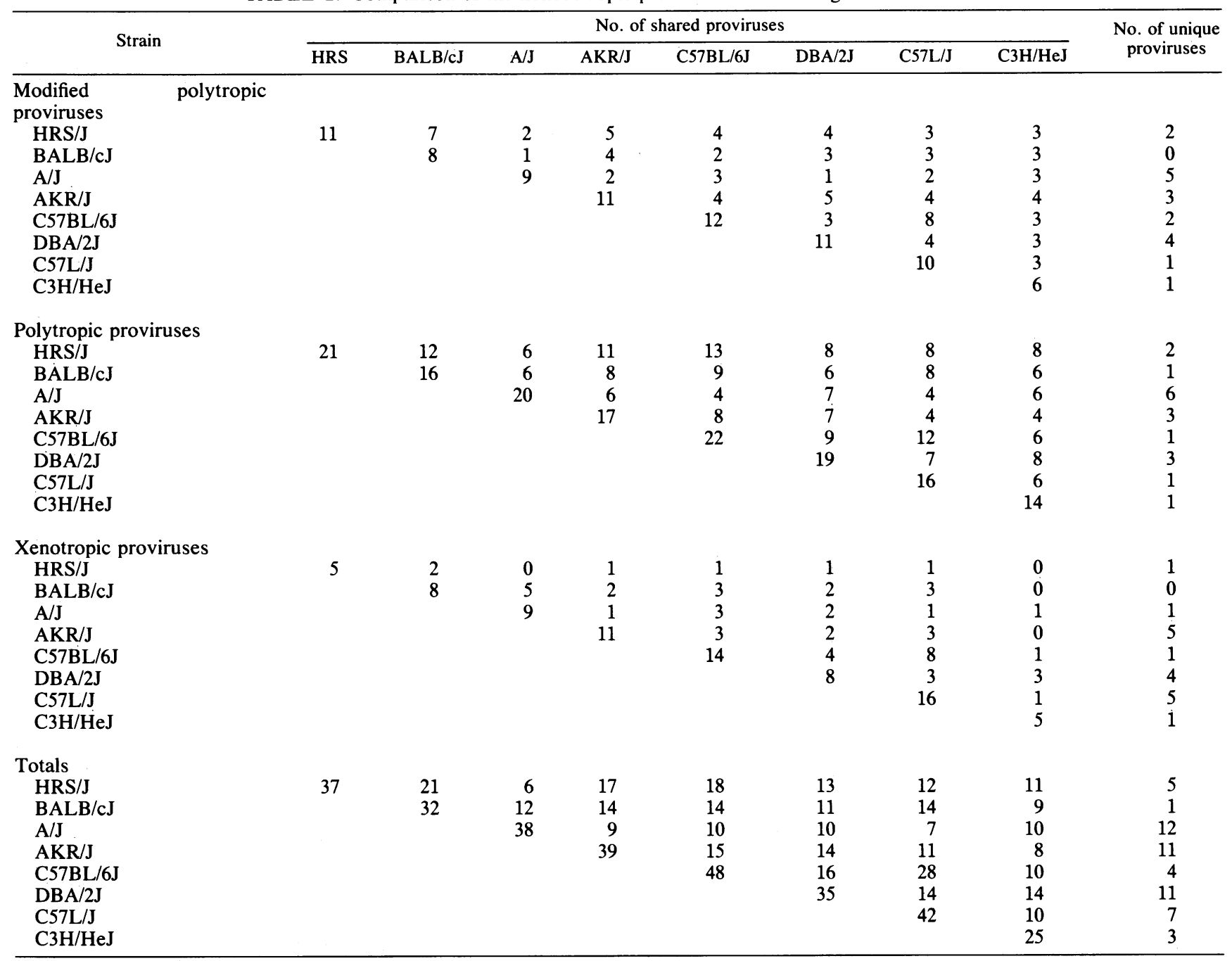

${ }^{a}$ In cases in which different estimates were derived from the $E c o$ RI and $P v u I I$ digests, the higher number was taken for the total number of proviruses in a given strain, and the lower number was taken for estimates of the number of shared proviruses.

we have initiated a survey of mutant mouse strains to look for association between novel proviruses and the specific mutations. Preliminary results indicate a close association between an endogenous polytropic provirus and the $h r$ mutation of $\mathrm{HRS} / \mathrm{J}$ mice.

\section{ACKNOWLEDGMENTS}

This work was supported by Public Health Service grant CA 24530 from the National Cancer Institute. J.P.S. was supported by a fellowship from the American Cancer Society, Massachusetts Division, Inc.

We thank Mary Bostic-Fitzgerald and Susan E. Morrison for assistance in preparation of the manuscript and numerous colleagues at Tufts for helpful discussions.

\section{LITERATURE CITED}

1. Biggin, M. D., T. J. Gibson, and G. F. Hong. 1983. Buffer gradient gels and ${ }^{35} \mathrm{~S}$ label as an aid to rapid DNA sequence determination. Proc. Natl. Acad. Sci. USA 80:3963-3965.

2. Blatt, C., K. Milehan, M. Haas, M. N. Nesbit, N. E. Harper, and M. I. Simon. 1983. Chromosomal mapping of the mink cell focus-inducing and enotropic env gene family in the mouse. Proc. Natl. Acad. Sci. USA 80:6298-6302.
3. Buckler, C. E., M. D. Hoggan, H. W. Chan, J. F. Sears, A. S. Khan, J. L. Moore, J. W. Hartley, W. P. Rowe, and M. A. Martin. 1982. Cloning and characterization of an envelopespecific probe from xenotropic murine leukemia proviral DNA. J. Virol. 41:228-236.

4. Casadaban, M. J., J. Chou, and S. N. Cohen. 1980. In vitro gene fusions that join an enzymatically active $\beta$-galactosidase segment to amino-terminal fragments of exogenous proteins: $E s c h$ erichia coli plasmid vectors for the detection and cloning of translational initiation signals. J. Bacteriol. 143:971-980.

5. Chattopadhyay, S. K., M. R. Lander, E. Rands, and D. R. Lowy. 1980. The structure of endogenous murine leukemia virus DNA in mouse genomes. Proc. Natl. Acad. Sci. USA 77:5774-5778.

6. Coffin, J. M. 1982. Endogenous retroviruses, p. 1109-1203. In R. Weiss, N. Teich, H. E. Varmus, and J. M. Coffin (ed.), Molecular biology of tumor viruses. Part III: RNA tumor viruses, vol. 1, 2nd ed. Cold Spring Harbor Laboratory, Cold Spring Harbor, N.Y.

7. Copeland, N. G., K. W. Hutchinson, and N. A. Jenkins. 1983. Excision of the DBA ecotropic provirus in dilute coat-color revertants of mice occurs by homologous recombination involving the viral LTRs. Cell 33:379-387.

8. Copeland, N. G., N. A. Jenkins, and B. K. Lee. 1983. Association of the lethal yellow $\left(A^{y}\right)$ coat color mutation with an ecotropic murine leukemia virus genome. Proc. Natl. Acad. Sci. 
USA 80:247-249.

9. Dolberg, D. S., L. T. Bacheler, and H. Fan. 1981. Endogenous type $\mathrm{C}$ retroviral sequences of mice are organized in a small number of virus-like classes and have been acquired recently. $J$. Virol. 40:96-106.

10. Ferris, S. D., R. D. Sage, and W. C. Wilson. 1982. Evidence from mtDNA sequences that common laboratory strains of mice are descended from a single female. Nature (London) 295:163165.

11. Fitch, W., and W. Atchley. 1985. Evolution in inbred strains of mice appears rapid. Science 228:1169-1175.

12. Hoggan, M. D., R. R. O'Neill, and C. A. Kozak. 1986. Nonecotropic murine leukemia viruses in BALB/c and NFS/N mice characterization of the BALB/C Bxv-I provirus and the single NFS endogenous xenotrope. J. Virol. 60:980-986.

13. Holland, C. A., J. Wozney, and N. Hopkins. 1983. Nucleotide sequence of the gp70 gene of murine retrovirus MCF 247. J. Virol. 47:413-420.

14. Jenkins, N. A., and N. G. Copeland. 1985. High frequency germline acquisition of ecotropic MuLV proviruses in SWR/J$\mathrm{RF} / \mathrm{J}$ hybrid mice. Cell 43:811-819.

15. Jenkins, N. A., N. G. Copeland, B. A. Taylor, and B. K. Lee. 1981. Dilute (d) coat colour mutation of DBA/2J mice is associated with the site of integration of an ecotropic MuLV genome. Nature (London) 293:370-374.

16. Jenkins, N. A., N. G. Copeland, B. A. Taylor, and B. K. Lee. 1982. Organization, distribution, and stability of endogenous ecotropic murine leukemia virus DNA in chromosomes of $M u s$ musculus. J. Virol. 43:26-36.

17. Khan, A. S., and M. A. Martin. 1983. Endogenous murine leukemia proviral long terminal repeats contain a unique 190 base-pair insert. Proc. Natl. Acad. Sci. USA 80:2699-2703.

18. Kozak, C. A. 1985. Susceptibility of wild mouse cells to exogenous infection with xenotropic leukemia viruses: control by a single dominant locus on chromosome 1. J. Virol. 55:690-695.

19. Kozak, C. A., and W. P. Rowe. 1980 . Genetic mapping of murine leukemia virus-inducing loci in five mouse strains. J. Exp. Med. 152:219-228

20. Levy, D. E., R. A. Lerner, and M. C. Wilson. 1985. Norma expression of polymorphic endogenous retroviral RNA containing segments identical to mink cell focus-forming virus. J. Virol. 56:691-700.

21. Maniatis, T., E. F. Fritsch, and J. Sambrook. 1982. Molecular cloning: a laboratory manual. Cold Spring Harbor Laboratory, Cold Spring Harbor, N.Y.

22. Meruelo, D., A. Rossomando, M. Offer, J. Buxbaum, and A. Pellicer. 1983. Association of endogenous viral loci with genes encoding murine histocompatibility and lymphocyte differentiation antigens. Proc. Natl. Acad. Sci. USA 80:5032-5036.

23. Messing, J., and J. Vieira. 1982. A new pair of M13 vectors for selecting either DNA strand of double-digest restriction fragments. Gene 19:269-276.

24. Morse, H. 1978. Origins of inbred mice. Academic Press, Inc.,
New York.

25. O'Neill, R. R., C. E. Buckler, T. S. Theodore, M. A. Martin, and R. Repaske. 1985. Envelope and long terminal sequences of a cloned infectious NZB xenotropic murine leukemia virus. J. Virol. 53:100-106.

26. O'Neill, R. R., A. S. Khan, M. D. Hoggan, J. W. Hartley, M. A. Martin, and R. Repaske. 1986. Specific hybridization probes demonstrate fewer xenotropic than mink cell focus-forming murine leukemia virus env-related sequences in DNAs from inbred laboratory mice. J. Virol. 58:359-366.

27. Ou, C.-Y., L. R. Boone, and W. K. Yang. 1983. A novel sequence element and the nucleotide structural features in the long terminal repeat of a BALB/c mouse genomic leukemia virus-related DNA clone. Nucleic Acids Res. 11:5603-5620.

28. Rein, A. 1982. Interference grouping of murine leukemia viruses: a distinct receptor of MCF-recombinant viruses in mouse cells. Virology 120:251-257.

29. Sanger, F., S. Nicklen, and A. R. Coulson. 1977. DNA sequencing with chain terminating inhibitors. Proc. Natl. Acad. Sci. USA 74:5463-5467.

30. Schnieke, A., K. Harbers, and R. Jaenisch. 1983. Embryonic lethal mutagen in mice induced by retrovirus insertion into the $\alpha 1$ (I) collagen gene. Nature (London) 304:315-319.

30a.Siracusa, L. D., L. B. Russell, N. A. Jenkins, and N. G. Copeland. 1987. Allelic variation within the $E m v-15$ locus defines cellular sequences closely linked to the agouti locus on mouse chromosome 2. Genetics 117:85-92.

31. Steffan, D. L., R. Mural, D. Cowing, J. Mielcarz, J. Young, and R. Roblin. 1982. Most of the murine leukemia virus sequences in the DNA of NIH/Swiss mice consist of two closely related proviruses, each repeated several times. J. Virol. 43:127135.

32. Stoye, J. P., and J. M. Coffin. 1985. Endogenous retroviruses, p. 357-404. In R. Weiss, N. Teich, H. E. Varmus, and J. M. Coffin (ed.), Molecular biology of tumor viruses. Part III: RNA tumor viruses, vol. 2, 2nd ed. Cold Spring Harbor Laboratory, Cold Spring Harbor, N.Y.

33. Stoye, J. P., and J. M. Coffin. 1987. The four classes of endogenous murine leukemia virus: structural relationships and potential for recombination. J. Virol. 61:2659-2669.

34. Stoye, J. P., and C. Moroni. 1983. Endogenous retrovirus expression in stimulated murine lymphocytes. Identification of a new locus controlling mitogen induction of a defective virus. $J$. Exp. Med. 157:1660-1674.

35. Weiss, R. A. 1982. Experimental biology and assay of RNA tumor viruses, p. 209-260. In R. Weiss, N. Teich, H. E. Varmus, and J. M. Coffin (ed.), Molecular biology of tumor viruses. Part III. RNA tumor viruses, vol. 1, 2nd ed. Cold Spring Harbor Laboratory, Cold Spring Harbor, N.Y.

36. Wejman, J. C., B. A. Taylor, N. A. Jenkins, and N. G. Copeland. 1984. Endogenous xenotropic murine leukemia virus-related sequences map to chromosomal regions encoding mouse lymphocyte antigens. J. Virol. 50:237-247. 